\title{
Ovarian Cancer Care Delivery: Diversity in Public Perception and Access to Care
}

\section{Cowan RA, Esposito-Amery P, Seier K, lasonos A, O'Cearbhaill R, Tew W, Jewell E, Brown C, Zivanovic O, Sonoda Y, Long-Roche, K, Abu-Rustum NR, Chi DS, Gardner GJ}

\section{BACKGROUND \& OBJECTIVE}

-There is growing data which demonstrates the value of high volume care centers staffed with high volume gynecologic oncology specialists for the treatment of advanced ovarian cancer.

- This study will play a key role in determining the public opinion of New York State residents with regard to ovarian cancer care delivery and can serve to generate hypotheses and develop interventions to address these perceptions.

-The objective of this study was to employ the Cornell University Empire State Poll to assess the public perceptions regarding ovarian cancer care delivery and the role of subspecialty care.

\section{PATIENTS \& METHODS}

-The Empire State Poll, first conducted in 2003, was the 16th annual general phone survey of approximately 800 adults (400 upstate, 400 downstate), age 18 and over, from randomly selected households within New York State.

-The Survey Research Institute of Cornell University conducted all surveys. Telephone data collection for the full study began on February 8, 2018 and ended on April 5, 2018.

-We contributed questions regarding ovarian cancer care delivery.

\section{RESULTS}

Table 1: Respondent Demographics

\section{Variable}

$\%(n)$

\begin{tabular}{|c|c|}
\hline Median Age (range) & $48(18-94)$ \\
\hline Male & 50 (399) \\
\hline Female & $50(401)$ \\
\hline \multicolumn{2}{|l|}{ Employment Status } \\
\hline Employed & $64(509)$ \\
\hline Unemployed & $18(143)$ \\
\hline Retired & $15(117)$ \\
\hline Disabled & $3(27)$ \\
\hline Unable to Work/Other & $0.4(3)$ \\
\hline \multicolumn{2}{|l|}{ Marital Status } \\
\hline Married & $47(373)$ \\
\hline Divorced & $10(76)$ \\
\hline Separated & $3(24)$ \\
\hline Widowed & $4(33)$ \\
\hline Single & $36(290)$ \\
\hline
\end{tabular}

Educational level

No education or grades 1-8

Some high school

$8(60)$

High School graduate

Technical, trade or vocational school after HS Some college

College graduate ( 4 yr degree)

19 (149)

Post grad training or professional schooling Race/Ethnicity

White

Black

$19(150)$

Other

Hispanic

Non-Hispanic

\section{Median Total Household Income (range)}

0 - under $\$ 75,000$

$\$ 75,000$ and above
If you (or a loved one) were diagnosed with ovarian cancer, what kind of doctor would you first see for treatment?

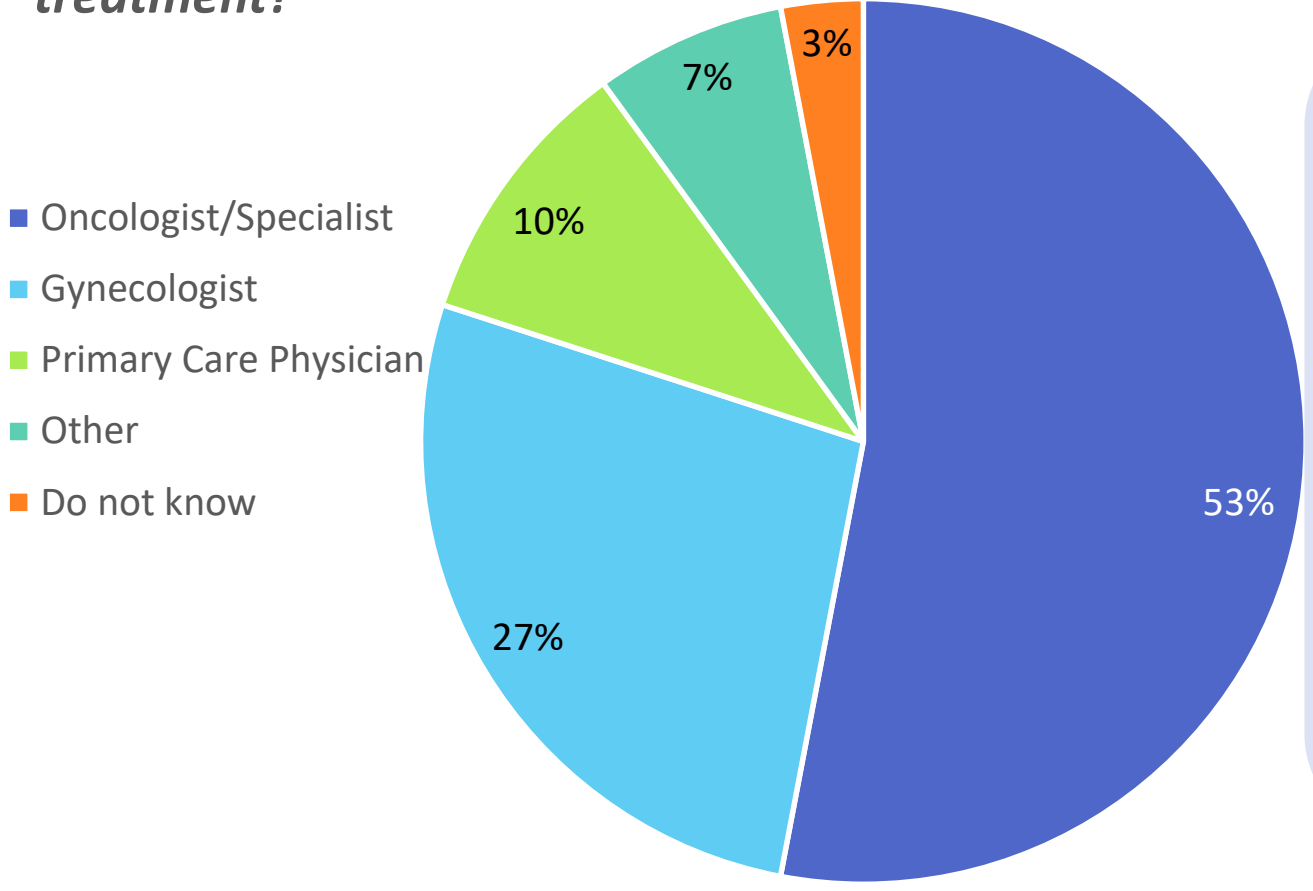

While all else is held constant respondents who are female, not married, and of "other" race were less likely to choose an oncologist and respondents with household incomes $>\$ 75 k$ were more likely to choose an oncologist.

If you (or a loved one) were diagnosed with ovarian cancer, how would you feel about clinical trials being a part of the cancer treatment experience?

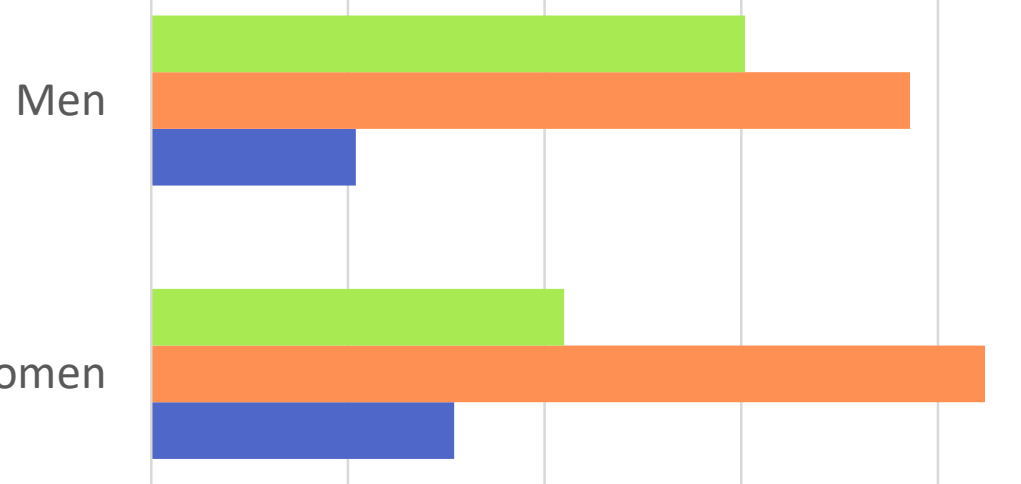
am indifferent to being involved in clinical trials
I believe that clinical trials would be beneficial
I would not like to be involved in any clinical trials

If you (or a loved one) were diagnosed with ovarian cancer, how far would you be willing to travel to see an ovarian cancer specialist for surgery?

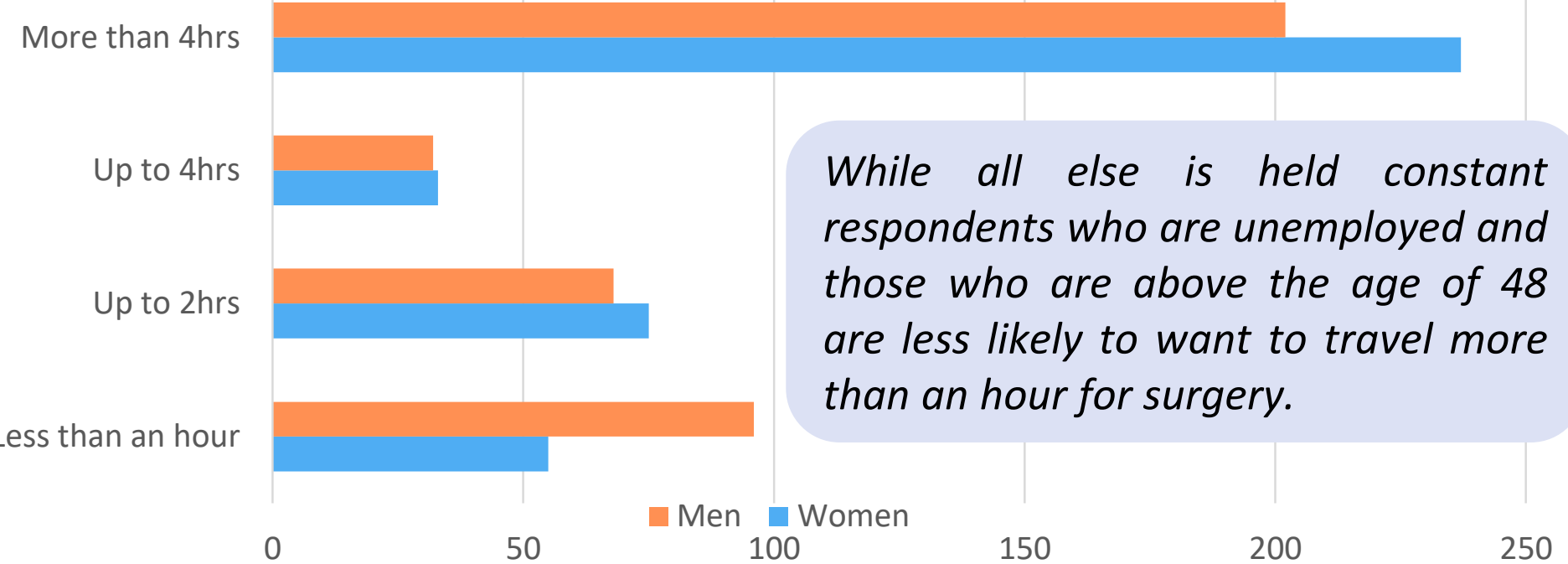

Have you ever been exposed to ovarian cancer education or awareness in your area?

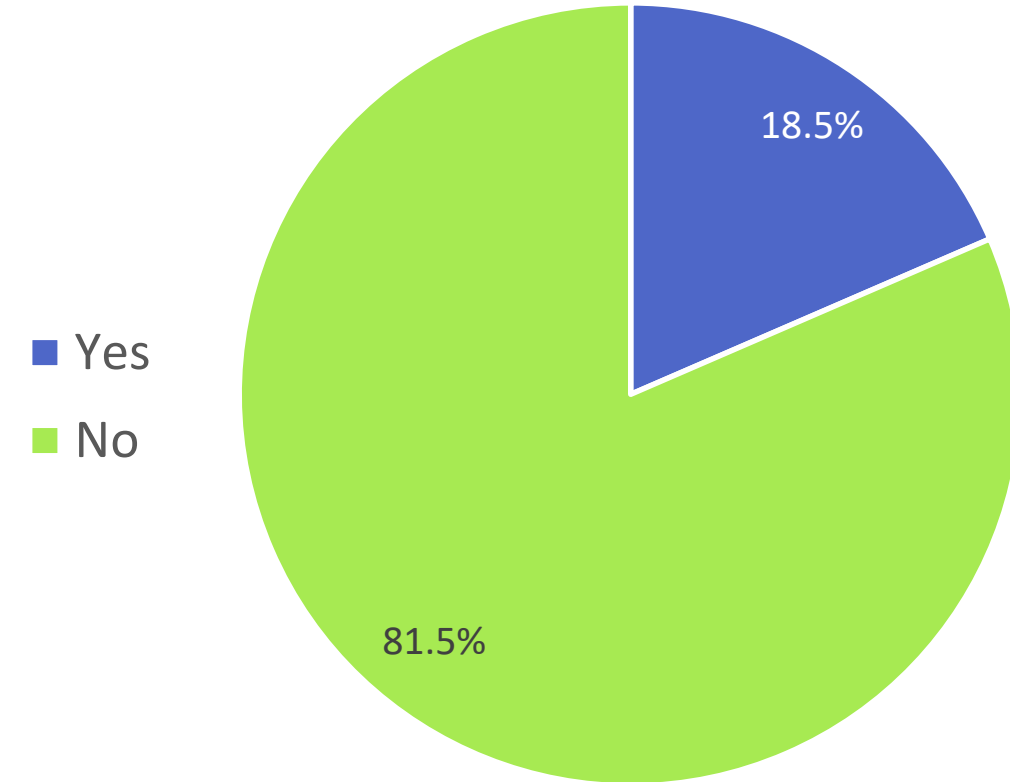

While all else is held constant respondents who live upstate or are female are more likely to have been exposed to an ovarian cancer awareness campaign; while those who are older were less likely to have been exposed. 